\title{
Disease-related information requirements in patients with Crohn's disease
}

This article was published in the following Dove Press journal:

Patient Preference and Adherence

\section{Qiangqiang Wu \\ Jie Zhong}

Department of Gastroenterology, Ruijin Hospital, School of Medicine, Shanghai Jiaotong University, Shanghai, People's Republic of China
Correspondence: Jie Zhong Department of Gastroenterology, Ruijin Hospital, School of Medicine, Shanghai Jiaotong University,

No 197, Ruijiner Road, Shanghai 200025, People's Republic of China Tel +86 2l 64370045 ext 600907 Email jimmyzj64@medmail.com.cn
Aim: To explore the demands for different disease-related information and the acceptance of various information sources in patients with Crohn's disease (CD).

Methods: This study included 159 patients with CD and was conducted from April 2017 to December 2017 in our hospital. We obtained the demographic characteristics of the patients and used the modified information demands questionnaire to assess patients' disease information demands, covering 4 aspects which include general knowledge, fertility, clinical treatment, and daily management. Then, we analyzed the factors associated with the information demand. In addition, we studied the patients' acceptance of different information sources.

Results: The disease-related information demands of patients with CD are generally high. Female patients, young patients, and patients with plans to have children have significantly higher information demands concerning fertility. The information demands in clinical treatment are higher in young patients. Patients living in the countryside and patients with a short disease duration have high information demands concerning life management. The patients' acceptance of different information sources is variable. Doctor-mediated guidance, brochures, and videos are the top 3 patient choices for information sources.

Conclusion: Patients' information demands concerning many aspects of CD are generally high. Certain demands are significantly associated with the demographic characteristics of the patients. Doctor-mediated guidance, brochures, and videos are the top 3 patient choices for information sources. Therefore, corresponding education programs can be developed to improve the physical and psychological health of CD patients in the future.

Keywords: Crohn's disease, information demand, influencing factor, information source

\section{Introduction}

Crohn's disease (CD) is a chronic nonspecific inflammatory disease affecting the full thickness of the intestinal wall and may affect any part of the digestive tract. The clinical manifestations are mainly abdominal pain and diarrhea. A long duration of illness and repeated flares can cause intestinal obstruction, intestinal perforation, intestinal fistulas, and perianal disease. The etiology of CD is still not clear. It may be related to genetic factors, microbial infection, and abnormal autoimmunity. ${ }^{1,2}$ To date, the disease is responsible for enormous social and financial burdens for patients and society, and has evolved to become one of the major health concerns in People's Republic of China. Several studies have reported that repeated flares of physical syndromes lead to the aggravation of anxiety and depression, ${ }^{3-5}$ which could have a negative effect on the quality of life $\mathrm{e}^{6,7}$ and social function ${ }^{8,9}$ of CD patients.

Studies show that inflammatory bowel disease (IBD) patients obtain significantly less disease information, compared with their information demands. ${ }^{10-13}$ Bernstein et $\mathrm{al}^{10}$ conducted a survey in newly diagnosed IBD patients and found that only $45 \%$ 
of the patients were very satisfied with the information they received, including basic information on the disease (including long-term prognosis, cancer risk, genetic risk, and fertility), clinical treatment (including drug side effects, pain, and drug adjustment), and self-management (including diet choose, how to communicate with family members, and how to seek support). The patients believed that this information was very important, but typically received minimal or no disease information. ${ }^{10}$ For example, $88 \%$ of the patients believed that information concerning the long-term prognosis of IBD was very important, but only $14 \%$ of the patients were provided with enough prognostic information. In a study of IBD patients with a long disease duration, the patients believed that information concerning the long-term disease prognosis, dietary awareness and selection, coping strategies, clinical symptom management, and drug side effects is very helpful. ${ }^{11}$

In terms of different sources of information, patients believe that specialists, family doctors, nurses, books, websites, and disease support groups are very easy to accept, and $68 \%$ of patients choose specialists as their preferred source of information. ${ }^{10}$ Becker et al ${ }^{14}$ also obtained similar results. In addition, Wong et $\mathrm{al}^{11}$ found that the most acceptable source of information is specialists, and most patients (51\%) make it their first choice, followed by books, family doctors, websites, and mutual assistance groups.

The purpose of the current study is to analyze the demand for disease-related information and to assess the acceptance of multiple information sources in patients with $\mathrm{CD}$, which will help with the development of education programs to improve patients' physical and psychological health in the future.

\section{Methods}

\section{Patient enrollment}

The ethics committee of Ruijin Hospital, which was affiliated with the School of Medicine at Shanghai Jiao Tong University, approved our study and written informed consent was obtained from all patients. This was a cross-sectional study. CD patients who were in clinical remission were enrolled through the outpatient clinic and hospitalization in the Department of Gastroenterology, Ruijin Hospital, Shanghai, People's Republic of China from April 2017 to December 2017.

\section{Inclusion and exclusion criteria}

The inclusion criteria included the following: 1) age between 14 and 70 years; 2) a definite diagnosis of CD; 3) disease duration of at least 6 months. The exclusion criteria included the following: 1) inability to read or write, 2) finished the questionnaires in no more than 15 minutes, 3) suffered from a known mental disorder, 4) complications with other diseases, and 5) patients who did not give consent.

\section{Measures and questionnaires}

\section{Demographic characteristics}

Basic patient information was collected, including gender, age, education level, marital status, occupation, habitat, childbearing history, plans to have children, disease duration, disease classification (Montreal classification), and disease-related operation history.

\section{Questionnaire to evaluate the information demand in patients with $C D$}

In the current study, a questionnaire designed by Bernstein et $\mathrm{a}^{10}$ was used to evaluate the information demands of patients with $\mathrm{CD}$ and revised by our group for the needs of the Chinese patients by adding accessible information concerning Chinese medicine treatments. The questionnaire can be divided into 4 aspects and consists of 20 items: general knowledge ( 5 items), fertility ( 2 items), clinical treatment ( 7 items), and daily management (6 items). Each question is assessed using a 9-point scale (0-8): 0 means no demand, 8 means an extreme demand, and a higher score for each item means a higher demand. In addition, the score is graded as follows: $0-2$ points represents a low demand; 3-5 points represents a general demand; 6-8 points represents a high demand. The questionnaire also assessed the patient's acceptance of 8 different information sources. Each aspect is assessed using a 9-point scale (0-8): 0 points means this source cannot be accepted, and 8 points means this source is very easy to accept. The higher the score is, the better the acceptance of the information source. In addition, we graded the score, $0-2$ points signifies that this source is not easy to accept; $3-5$ points source signifies that this source is generally accepted; $6-8$ points signifies that this source is easily accepted. Finally, the sources were sorted according to their degree of acceptance.

\section{Data collection}

All patients were informed of the research purpose and methods of this study. After the patient's informed consent was obtained, the researchers explained the requirements of the questionnaire. All the patients filled out the questionnaire independently, and the researchers retrieved the questionnaire 15 minutes later. 


\section{Statistical analysis}

SPSS 21.0 (IBM Corporation, Armonk, NY, USA) was used for data analysis, and the demographic characteristics of the patients were described using $\mathrm{N}$ and percentages (\%). The information demand scores and the percentage of patients with high acceptability for different types of information, including information on general knowledge, fertility, clinical treatment, and daily management, were calculated and analyzed. The independent $t$-tests and one-way ANOVA were used to analyze the correlation between the demographic characteristics and the demand for information concerning general knowledge, clinical treatment, fertility, and daily management. Variables influencing the demand for information about fertility were simultaneously included in the multivariable analysis. The score for the acceptance of different information sources and the proportion of patients with a high acceptance of different information sources were calculated and analyzed. All sources were sorted according to the patient first choose. $P<0.05$ was considered to indicate a statistically significant difference.

\section{Results}

\section{Demographic characteristics}

From April 2017 to December 2017, a total of 159 patients were enrolled and completed the questionnaires. The demographic characteristics of these patients are listed in Table 1.

\section{The demand for different types of information in $C D$ patients}

As shown in Table 2, 77\%-87\% of patients had high demand for general disease-related information, including clinical symptoms, complications, etiology, prognosis, and risk of cancer. Patients had less demand for fertility-related information compared with general information concerning the disease. Only 64\%-69\% patients showed a high demand for fertility-related information. There were significant disparities between the level of demands for information concerning clinical treatments for CD patients. Most patients (70\%-91\%) had high demand for information concerning drug treatments, side effects of drugs, medication adjustments, and regular follow-ups. Only $35.2 \%-50.9 \%$ of patients showed a high demand for information concerning Chinese medicine treatments and moxibustion treatments. The demand for information about daily management in $\mathrm{CD}$ patients was generally higher than that for other topics. Finally, 71\%-93\% of patients showed a high demand for information about
Table I Patient's demographic characteristics

\begin{tabular}{|c|c|}
\hline Content & Patients (\%) \\
\hline \multicolumn{2}{|l|}{ Gender } \\
\hline Male & II4 (7I.7) \\
\hline Female & $45(28.3)$ \\
\hline \multicolumn{2}{|l|}{ Age (years) } \\
\hline$\leq 25$ & $61(38.4)$ \\
\hline $26-35$ & $59(37.1)$ \\
\hline $36-45$ & $21(13.2)$ \\
\hline$\geq 46$ & $18(11.3)$ \\
\hline \multicolumn{2}{|l|}{ Education background } \\
\hline Elementary education & $6(3.8)$ \\
\hline Secondary education & $36(22.6)$ \\
\hline Higher education & $117(73.6)$ \\
\hline \multicolumn{2}{|l|}{ Marital status } \\
\hline Unmarried & $78(49.1)$ \\
\hline Married & $81(50.9)$ \\
\hline \multicolumn{2}{|l|}{ Social status } \\
\hline Student & $37(23.3)$ \\
\hline Employment & $91(57.2)$ \\
\hline Unemployment & $31(19.5)$ \\
\hline \multicolumn{2}{|l|}{ Region } \\
\hline City & III (69.8) \\
\hline Countryside & $48(30.2)$ \\
\hline \multicolumn{2}{|l|}{ Childbearing history } \\
\hline With & $66(4 I .5)$ \\
\hline Without & $93(58.5)$ \\
\hline \multicolumn{2}{|l|}{ Plans to have children } \\
\hline With & $32(20.1 \%)$ \\
\hline Without & 127 (79.9\%) \\
\hline \multicolumn{2}{|l|}{ Disease duration (year) } \\
\hline$<1$ & $55(34.6)$ \\
\hline $\mathrm{I}-5$ & $73(45.9)$ \\
\hline$>5$ & $31(19.5)$ \\
\hline \multicolumn{2}{|l|}{ Age of onset $(A)$} \\
\hline$<I 7(\mathrm{Al})$ & $19(11.9)$ \\
\hline $17-40(\mathrm{~A} 2)$ & $123(77.4)$ \\
\hline$>40(\mathrm{~A} 3)$ & $17(10.7)$ \\
\hline \multicolumn{2}{|l|}{ Location (L) } \\
\hline Terminal ileum (LI) & $56(35.2)$ \\
\hline Colon (L2) & $12(7.5)$ \\
\hline Ileocolon (L3) & $89(56.0)$ \\
\hline Upper gastrointestinal tract (L4) & $2(1.3)$ \\
\hline \multicolumn{2}{|l|}{ Behavior (B) } \\
\hline Nonpenetrating and nonstenosing $(\mathrm{BI})$ & $97(61.0)$ \\
\hline Stenosing (B2) & $4 \mid(25.8)$ \\
\hline Penetrating (B3) & $21(13.2)$ \\
\hline \multicolumn{2}{|l|}{ Perianal lesions $(\mathrm{P})$} \\
\hline With & $67(42.1)$ \\
\hline Without & $92(57.9)$ \\
\hline \multicolumn{2}{|l|}{ CD-related surgery history } \\
\hline With & $74(46.5)$ \\
\hline Without & $85(53.5)$ \\
\hline
\end{tabular}

Notes: Elementary education: Sprimary school, junior middle school; secondary education: senior high school; higher education: $\geq$ university.

Abbreviation: $C D$, Crohn's disease. 
Table 2 The information demand in terms of the different aspects in CD patients

\begin{tabular}{|c|c|c|c|}
\hline Aspects & Content & Mean rating $(95 \% \mathrm{Cl})$ & $\begin{array}{l}\text { Rated as high } \\
\text { demand (\%) }\end{array}$ \\
\hline \multirow[t]{5}{*}{ General knowledge } & Clinical symptoms & $6.60(6.33-6.85)$ & $123(77.3)$ \\
\hline & Complications & $7.04(6.80-7.26)$ & $135(84.9)$ \\
\hline & Etiology & $6.65(6.92-6.38)$ & $126(79.2)$ \\
\hline & Prognosis & $6.99(6.78-7.20)$ & $137(86.2)$ \\
\hline & Risk of cancer & $6.76(6.47-7.05)$ & $127(79.9)$ \\
\hline \multirow[t]{2}{*}{ Fertility } & Pregnant & $6.21(5.86-6.66)$ & $110(69.2)$ \\
\hline & Heredity & $6.10(5.74-6.46)$ & $102(64.2)$ \\
\hline \multirow[t]{7}{*}{ Clinical treatment } & Drug treatment & $7.36(7.16-7.56)$ & $|4|(88.7)$ \\
\hline & Side effects of drugs & $6.75(6.48-7.00)$ & $123(77.4)$ \\
\hline & Medication adjustment & $7.37(7.20-7.54)$ & 145 (9l.2) \\
\hline & Surgical treatment & $6.20(5.89-6.5 I)$ & $110(69.2)$ \\
\hline & Chinese medicine treatment & $5.35(4.98-5.72)$ & $81(50.9)$ \\
\hline & Moxibustion therapy & $4.55(4.14-4.94)$ & $56(35.2)$ \\
\hline & Regular follow-up & $6.91(6.67-7.15)$ & $128(80.5)$ \\
\hline \multirow[t]{6}{*}{ Daily management } & Diet choices in active period & $7.40(7.21-7.59)$ & $147(92.5)$ \\
\hline & Diet choices in CD remission & $6.97(6.72-7.22)$ & I $30(8 \mid .8)$ \\
\hline & Eternal nutrition choices and timing & $6.64(6.35-6.91)$ & $125(78.6)$ \\
\hline & Life management & $7.13(6.94-7.32)$ & |4| (88.7) \\
\hline & Prevention during learning or work & $6.51(6.22-6.78)$ & II 8 (74.2) \\
\hline & Knowledge popularization in family & $6.45(6.16-6.72)$ & $113(7 \mid .1)$ \\
\hline
\end{tabular}

Abbreviation: CD, Crohn's disease.

diet choices during a period of active disease, diet choices during CD remission, enteral nutrition choices, and lifestyle management.

\section{Influencing factors associated with the information demand}

The correlations between the demographic characteristics and the demand for disease-related information were analyzed. The results are shown in Table 3 . The demand for fertility information has a significant correlation with gender, age, plans to have children, age of disease onset, disease behavior, and perianal lesions, for which female patients, young patients, patients with plans to have children, and patients with a young age of disease onset have a significantly higher demand than male patients $(P=0.007)$, older patients $(P=0.001)$, patients with no plans to have children $(P=0.010)$, and patients with an older age of onset ( $P=0.004)$. Moreover, patients with nonstenosis nonpenetrating type disease (B1) had higher demand for information than patients with stenosis disease (B2), and patients with stenosis type disease (B2) had higher demand for information than patients with penetration type disease (B3) $(P=0.011)$. Patients with perianal disease showed a higher demand for information than patients without perianal lesions $(P=0.020)$. The influence of many possible factors on the demand for fertility information was calculated using a logistic regression analysis (Table 4). Only gender, age, and plans to have children were found to independently predict the demand of fertility information. In clinical treatment, there was a significant negative correlation between the demand for information and the age of the patients $(P=0.047)$. For daily management, the information demand of patients showed a significant correlation with region and disease duration, with patients living in the countryside having higher demand than patients living in the city $(P=0.027)$ and patients suffering with long duration of illness having a lower demand than newly diagnosed patients $(P=0.047)$.

\section{The acceptance of different sources of information in patients with $C D$}

The degree of acceptance of different information sources in CD patients is different, and these results are shown in Table 5. A total of $83 \%-94 \%$ of patients had a high acceptance of information from doctors, brochures, and video sources. Doctor-mediated guidance, brochures, and videos were the top 3 first choices as preferred information sources for patients.

\section{Discussion}

$\mathrm{CD}$ is a chronic IBD with various clinical symptoms and recurrent attacks. Studies show that IBD management should not be limited to clinical diagnosis and treatment, but also needs to strengthen the patient's knowledge education and self-management so as to improve the disease 
Table 3 Correlation between information demands and demographic characteristics

\begin{tabular}{|c|c|c|c|c|}
\hline Content & Factor & Group & Mean rating & $P$-value \\
\hline \multirow[t]{16}{*}{ Fertility } & Gender & Male & $5.9 \pm 2.1$ & 0.007 \\
\hline & & Female & $6.7 \pm 1.5$ & \\
\hline & Age (years) & $\leq 25$ & $6.3 \pm 2.0$ & 0.001 \\
\hline & & $26-35$ & $6.7 \pm 1.6$ & \\
\hline & & $36-45$ & $5.5 \pm 1.7$ & \\
\hline & & $\geq 46$ & $4.6 \pm 2.5$ & \\
\hline & Thoughts of childbearing & With & $7.0 \pm 1.4$ & 0.010 \\
\hline & & Without & $6.0 \pm 2.0$ & \\
\hline & Age of onset (years) & $<17(\mathrm{Al})$ & $6.2 \pm 2.2$ & 0.004 \\
\hline & & $17-40(\mathrm{~A} 2)$ & $6.3 \pm 1.8$ & \\
\hline & & $>40(\mathrm{~A} 3)$ & $4.6 \pm 2.3$ & \\
\hline & Disease behavior & $\begin{array}{l}\text { Nonpenetrating and } \\
\text { nonstenosing }(\mathrm{BI})\end{array}$ & $6.5 \pm 1.7$ & 0.011 \\
\hline & & Stenosing (B2) & $5.9 \pm 2.0$ & \\
\hline & & Penetrating (B3) & $5.1 \pm 2.4$ & \\
\hline & Perianal lesions & With & $6.6 \pm 1.5$ & 0.020 \\
\hline & & Without & $5.8 \pm 2.2$ & \\
\hline \multirow[t]{4}{*}{ Clinical treatment } & Age (years) & $\leq 25$ & $6.4 \pm 1.2$ & 0.047 \\
\hline & & $26-35$ & $6.5 \pm 1.1$ & \\
\hline & & $36-45$ & $6.2 \pm 1.2$ & \\
\hline & & $\geq 46$ & $5.7 \pm 0.9$ & \\
\hline \multirow[t]{5}{*}{ Daily management } & Region & City & $6.7 \pm 1.2$ & 0.027 \\
\hline & & Countryside & $7.1 \pm 0.8$ & \\
\hline & Disease duration (years) & $<1$ & $7.1 \pm 0.9$ & 0.047 \\
\hline & & $\mathrm{I}-5$ & $6.7 \pm 1.2$ & \\
\hline & & $>5$ & $6.6 \pm 0.9$ & \\
\hline
\end{tabular}

Abbreviation: $C D$, Crohn's disease.

prognosis. ${ }^{15,16}$ However, IBD patients have a significantly lower level of information acquisition compared with their demand for information in areas of interested. ${ }^{10-13}$ The current study investigated the demand for information about general information, fertility, clinical treatments, and daily management in $\mathrm{CD}$ patients and analyzed the correlation between demographic characteristics and the demand for different types of information, so as to strengthen the patient education. We also discovered the differing acceptability of a variety of information sources in CD patients, which relates to the design of relevant educational programs.

In the current study, we discovered that $\mathrm{CD}$ patients have a high overall demand for information in various aspects (the proportion of patients with a high demand was approximately between $70 \%$ and $90 \%$ ). In terms of general knowledge about the disease, patients tend to demand information about the prognosis of the disease, complications, risk of cancer, and etiology, but have a low demand for information about clinical symptoms. This may be because the recurrent clinical symptoms are most closely related to quality of life, mental health, social function, and ability to work, and therefore patients have already gained relevant information. As for the other aspects of general knowledge, most of the patients in the current study were in the early stage of the disease ( $80.5 \%$ of patients had a disease duration of $<5$ years) and were usually not actively looking for such information, and therefore showed a high demand for information about these issues. In clinical treatment, CD patients have a high demand

Table 4 Logistic regression analysis of the information demand in terms of the aspect of fertility

\begin{tabular}{llll}
\hline Variables & $\begin{array}{l}\text { Estimated } \\
\text { coefficient }\end{array}$ & Odds ratio (95\% Cl) & $P$-value \\
\hline Gender (female) & 1.162 & $3.20(1.39-7.35)$ & 0.006 \\
Age ( $>35$ years old) & -1.503 & $0.22(0.10-0.5 I)$ & 0.000 \\
Plan to have children (without) & -0.950 & $0.39(0.15-0.99)$ & 0.048 \\
\hline
\end{tabular}


Table 5 The acceptance of different information sources

\begin{tabular}{llll}
\hline Content & Mean rating (95\% Cl) & $\begin{array}{l}\text { Rated as easily } \\
\text { accepted (\%) }\end{array}$ & $\begin{array}{l}\text { Ranked as } \\
\text { first choice (\%) }\end{array}$ \\
\hline Brochure & $7.03(6.81-7.23)$ & $134(84.3)$ & 8.8 \\
Doctor & $7.53(7.36-7.68)$ & $150(94.3)$ & 78.6 \\
Video & $6.95(6.73-7.15)$ & $132(83.0)$ & 1.9 \\
Website & $6.70(6.45-6.95)$ & $119(74.8)$ & 4.4 \\
Support group & $6.55(6.29-6.81)$ & $116(73.0)$ & 1.9 \\
Nurse & $6.57(6.32-6.82)$ & $118(74.2)$ & 0.0 \\
Pharmacist & $6.39(6.10-6.68)$ & $112(70.4)$ & 1.3 \\
Family member & $6.28(5.99-6.57)$ & $106(66.7)$ & 3.1 \\
\hline
\end{tabular}

for information about drug treatments, side effects of drugs, medication adjustments, and regular follow-ups. This is probably because $\mathrm{CD}$ patients lack a complex professional clinical knowledge of CD. Moreover, patients need timely adjustment during recurrent periods of the disease when they cannot see the doctor for some reason, so patients hope to obtain relevant information to help in these circumstances. However, patients' demand for information about traditional Chinese medicine was generally not high (the proportion of patients with a high demand ranged from 35.2\%-50.9\%), which may be because traditional Chinese medicine is not a first-line treatment plan for CD. Many patients have a waitand-see attitude. In daily management, patients' information demands for dietary choices and lifestyle management were generally high (the high demand proportion was 79\%-93\%), which may be most closely related to their daily demands. However, the demand for information about preventive measures during work or learning activities and knowledge popularization in the family was low. This may be because some patients (19.5\%) were currently unemployed, which can reduce interactions with the public or colleagues during active disease periods, and therefore the demand for information related to preventive measures is relatively low. In addition, younger patients (the average age is $31.3 \pm$ 10.7 years), of whom 61 (38.4\%) patients were under the age of 25 , were accompanied by family members during the clinic and hospitalization, which means that family members also have access to a large amount of disease-related knowledge, and therefore the information demand for IBD knowledge popularization is relatively low.

Researchers have discovered that the fertility potential of IBD patients is not significantly different from that of the healthy population, but the fertility rate in IBD patients is significantly low. ${ }^{17-19} \mathrm{CD}$ can influence pregnancy and heredity. The decision to have children is negatively related to disease-related knowledge, which means that patients without disease-related knowledge are more inclined to avoid having children. ${ }^{17-21}$ Mountifield et al ${ }^{20,21}$ studied IBD patients in sexual maturity period and found out that $42.7 \%$ of these patients are worried about fertility problems, and that female patients are more worried about fertility problems than male patients. The current study found that patients want relatively less information on fertility (patients with high demands accounted for $64.2 \%-69.2 \%$ ), which is consistent with earlier research $(66 \%-73 \%),{ }^{10}$ and this may be because the current study included only 32 patients $(20.1 \%)$ with plans to have children, who hope to find relevant information to avoid risks associated with $\mathrm{CD}$, so as to achieve safe pregnancy. As $41.5 \%$ of the patients already have offspring, they were more concerned about the hereditary nature of the disease, in regard to their offspring. Moreover, the demand for information about fertility is correlated with gender, age, and plans to have children. Female patients, young patients, and patients with plans to have children have significantly higher demands for information. This is because with medical advances, the disease can be controlled, so many women of a gestational age have a desire for fertility and obviously have a high demand for related knowledge. Whether patients with a young age of onset, patients with good disease behavior (B1), and patients with perianal lesions have a significantly higher demand for information needs further research.

In addition, there is no correlation between information demands for general knowledge and patient demographic characteristics, which means that patients have the same demands for this type of information. We also analyzed the correlation between the information demands for clinical treatment and daily management and patients' demographic characteristics, which showed that there was no correlation between the demand for information about clinical treatment and many demographic characteristics, but a negative correlation with the age of the patient, which means that younger patients have a higher information demand for information about clinical treatment. This may be because young patients have a higher need for quality of life, mental health, and 
social function compared with older patients. For the daily management, there was a significant correlation between the demand for information and habitat and disease duration, whereby patients who live in the countryside and those with a long duration of disease have higher demand for information compared with patients who live in the city and those with a short disease duration, respectively. Patients who live in the countryside lack medical resources and health education compared with patients living in the city. Moreover, patients with a short disease duration obviously lack information compared with patients with a long disease duration.

Doctors have significant levels of knowledge and rich experience in medicine. Therefore, patients readily accept information from doctors, and this was the top choice (78.6\%) as a patient information source. In addition, IBD-related knowledge brochures and videos were also readily accepted by patients. The proportion of patients making these first choices was $8.8 \%$ and $4.4 \%$, respectively, which is consistent with Bernstein et al's results. ${ }^{10}$ Recent studies have found that doctor-mediated disease education transmitted orally is difficult for patients to remember, especially when there is a lot of information transmitted. Patients often fail to remember information correctly, resulting in memory loss or even memory errors. ${ }^{22,23}$ Therefore, the use of brochures or videos is more likely to improve the effectiveness and convenience of information transmission. ${ }^{24}$ For example, targeted guidance through design materials or websites can make health education more effective. ${ }^{25,26}$ At present, some related educational projects have been carried out by some researchers and good results have been achieved. ${ }^{27,28}$

There are still many limitations in this study. First, this study lacks an evaluation of CD activity. Future research should include a patient disease activity score so as to evaluate differences in the information demands of patients during different periods of disease. Second, the different types of included disease information still need to be improved in this research, to achieve a more thorough evaluation of information demands. In addition, the sample size should be further increased in future research. Finally, the study lacks suggestions for relevant health education programs to meet patients' information demands, which should be discussed in future research.

\section{Conclusion}

The disease-related information demands of patients with $\mathrm{CD}$ are generally high and are influenced by many variables. Patient acceptance of different information sources is variable. Doctor-mediated guidance is the patients' first choice from the available information sources.

\section{Acknowledgment}

This study was supported by National Natural Science Foundation of China (no 81670503).

\section{Author contribution}

All authors contributed toward data analysis, drafting and revising the paper, and agree to be accountable for all aspects of the work.

\section{Disclosure}

The authors report no conflicts of interest in this work.

\section{References}

1. Michielan A, D'Incà R. Intestinal permeability in inflammatory bowel disease: pathogenesis, clinical evaluation, and therapy of leaky gut. Mediators Inflamm. 2015;2015(5):1-10.

2. Malik TA. Inflammatory bowel disease: historical perspective, epidemiology, and risk factors. Surg Clin North Am. 2015;95(6): 1105-1122.

3. Goodhand JR, Wahed M, Mawdsley JE, Farmer AD, Aziz Q, Rampton DS Mood disorders in inflammatory bowel disease: relation to diagnosis, disease activity, perceived stress, and other factors. Inflamm Bowel Dis. 2012;18(12):2301-2309.

4. Mikocka-Walus A, Knowles SR, Keefer L, Graff L. Controversies revisited: a systematic review of the comorbidity of depression and anxiety with inflammatory bowel diseases. Inflamm Bowel Dis. 2016; 22(3):752-762.

5. Walker JR, Ediger JP, Graff LA, et al. The Manitoba IBD cohort study: a population-based study of the prevalence of lifetime and 12-month anxiety and mood disorders. Am J Gastroenterol. 2008; 103(8):1989.

6. Irvine EJ. Quality of life issues in patients with inflammatory bowel disease. Am J Gastroenterol. 1997;92(Suppl 12):18S-24S.

7. Drossman DA, Patrick DL, Mitchell CM, Zagami EA, Appelbaum MI Health-related quality of life in inflammatory bowel disease. Dig Dis Sci. 1989;34(9):1379-1386.

8. Mackner LM, Vannatta K, Crandall WV. Gender differences in the social functioning of adolescents with inflammatory bowel disease. J Clin Psychol Med Settings. 2012;19(3):270-276.

9. Ross S. A Comparison of Psychosocial Functioning Between Early, Mid and Late Adolescence in Young People with Inflammatory Bowel Disease, and Clinical Research Portfolio [D Clin Psy thesis]. Glasgow, Scotland: University of Glasgow; 2010.

10. Bernstein KI, Promislow S, Carr R, Rawsthorne P, Walker JR, Bernstein CN. Information needs and preferences of recently diagnosed patients with inflammatory bowel disease. Inflamm Bowel Dis. 2011; 17(2):590-598.

11. Wong S, Walker JR, Carr R, et al. The information needs and preferences of persons with longstanding inflammatory bowel disease. Can J Gastroenterol Hepatol. 2012;26(8):525-531.

12. Martin A, Leone L, Castagliuolo I, Di Mario F, Naccarato R. What do patients want to know about their inflammatory bowel disease? Ital $J$ Gastroenterol. 1991;24(9):477-480.

13. Mansfield JC, Tanner AR, Bramble MG. Information for patients about inflammatory bowel disease. J R Coll Physicians Lond. 1997;31(2): 184-187.

14. Becker HM, Grigat D, Ghosh S, et al. Living with inflammatory bowel disease: a Crohn's and Colitis Canada survey. Can J Gastroenterol Hepatol. 2015;29(2):77-84.

15. Mowat C, Cole A, Windsor A, et al. Guidelines for the management of inflammatory bowel disease in adults. Gut. 2011;60(5):571-607. 
16. Dulai PS, Singh S, Ohno-Machado L, Sandborn WJ. Population health management for inflammatory bowel disease. Gastroenterology. 2018; 154(1):37-45.

17. Nguyen GC, Seow CH, Maxwell C, et al. The Toronto consensus statements for the management of inflammatory bowel disease in pregnancy. Gastroenterology. 2016;150(3):734.e1-757.e1.

18. van der Woude CJ, Ardizzone S, Bengtson MB, et al. The second European evidenced-based consensus on reproduction and pregnancy in inflammatory bowel disease. J Crohns Colitis. 2015;9(2):107-124.

19. Hudson M, Flett G, Sinclair TS, Brunt PW, Templeton A, Mowat NA. Fertility and pregnancy in inflammatory bowel disease. Int J Gynaecol Obstet. 2001;58(4):455-459.

20. Mountifield R, Bampton P, Prosser R, Muller K, Andrews JM. Fear and fertility in inflammatory bowel disease: a mismatch of perception and reality affects family planning decisions. Inflamm Bowel Dis. 2009;15(5):720-725.

21. Mountifield RE, Prosser R, Bampton P, Muller K, Andrews JM. Pregnancy and IBD treatment: this challenging interplay from a patients' perspective. J Crohns Colitis. 2010;4(2):176-182.

22. Kessels RPC. Patients' memory for medical information. JR Soc Med. 2003;96(10):520.
23. Jansen $J$, van Weert J, van der Meulen N, van Dulmen S, Heeren T, Bensing J. Recall in older cancer patients: measuring memory for medical information. Gerontologist. 2008;48(2):149-157.

24. Watson PW, Mckinstry B. A systematic review of interventions to improve recall of medical advice in healthcare consultations. $J R$ Soc Med. 2009;102(6):235-243.

25. Jolles EP, Clark AM, Braam B. Getting the message across: opportunities and obstacles in effective communication in hypertension care. J Hypertens. 2012;30(8):1500-1510.

26. Farrell EH, Whistance RN, Phillips K, et al. Systematic review and meta-analysis of audio-visual information aids for informed consent for invasive healthcare procedures in clinical practice. Patient Educ Couns. 2014;94(1):20-32.

27. Oxelmark L, Magnusson A, Löfberg R, Hillerås P. Group-based intervention program in inflammatory bowel disease patients: effects on quality of life. Inflamm Bowel Dis. 2007;13(2):182-190.

28. Boamah LM, Bohren JR, Pentiuk S, et al. Development and testing of a CD-ROM program for improving adolescent knowledge of inflammatory bowel disease. J Pediatr Gastroenterol Nutr. 2010;50(5):521-525.
Patient Preference and Adherence

\section{Publish your work in this journal}

Patient Preference and Adherence is an international, peer-reviewed, open access journal that focuses on the growing importance of patient preference and adherence throughout the therapeutic continuum. Patient satisfaction, acceptability, quality of life, compliance, persistence and their role in developing new therapeutic modalities and compounds to optimize

\section{Dovepress}

clinical outcomes for existing disease states are major areas of interest for the journal. This journal has been accepted for indexing on PubMed Central. The manuscript management system is completely online and includes a very quick and fair peer-review system, which is all easy to use. Visit http://www dovepress.com/testimonials.php to read real quotes from published authors. 